\title{
Decreased MUC1 in endometrium is an independent receptivity marker in recurrent implantation failure during implantation window
}

\author{
Fangrong Wu', Xiaoyan Chen ${ }^{1}$, Yingyu Liu ${ }^{1}$, Bo Liang ${ }^{1}$, Hui Xu' ${ }^{1}$, Tin Chiu Li ${ }^{1}$ and Chi Chiu Wang ${ }^{1,2,3^{*}}$
}

\begin{abstract}
Background: It is postulated that women suffered from recurrent implantation failure (RIF) have different endometrial receptivity compared to those who experienced with idiopathic recurrent miscarriage (RM). In this study, expression of common endometrial markers Leukemia inhibitor factor (LIF), mucin 1 (MUC1) and integrin $\beta 3$ were studied and compared.

Methods: Fourteen women with RIF, 25 with RM and 20 fertile controls were recruited for endometrial biopsy during implantation window on day LH + 7. Spatial and temporal expression of MUC1, LIF and Integrin $\beta 3$ were compared using semi-quantitative immunohistochemistry. Association of MUC1, LIF and integrin $\beta 3$ expression levels with demographic and clinical characteristics were determined.

Results: MUC1 expression in both luminal and glandular epithelium in women with RIF were significantly lower than that in women with RM and fertile controls. There were no differences in LIF and Integrin $\beta 3$ expression in endometrial epithelium among three groups. Decreased MUC1 expression were not significantly associated with age, BMl, gravidity, parity, cycle length, progesterone level and previous miscarriage.

Conclusions: Deceased expression of MUC1 is an independent marker for endometrial receptivity in RIF women, suggesting MUC1 may contribute to the reproductive failure in RIF women.
\end{abstract}

Keywords: Implantation, Endometrium, Receptivity markers, Reproductive failure

\section{Introduction}

Endometrium is critical for a successful implantation [1]. For only a short period of time during mid-luteal phase, the endometrium becomes receptive to the embryo to implant. This specific period has been referred as implantation window around 7 days after surge of luteinizing hormone $(\mathrm{LH}+7)$ [2]. During this implantation window, endometrium will equip with adhesion

\footnotetext{
* Correspondence: ccwang@cuhk.edu.hk

Paper presentation information: Part of this work was presented at the $7^{\text {th }}$ congress of the Asia Pacific Initiative on Reproduction (ASPIRE 2017) held in Kuala Lumper, Malaysia, 30 March-2 April 2017

'Department of Obstetrics and Gynaecology, The Chinese University of Hong Kong, Shatin, Hong Kong

${ }^{2}$ Li Ka Shing Institute of Health Sciences, Faculty of Medicine, The Chinese

University of Hong Kong, Shatin, Hong Kong

Full list of author information is available at the end of the article
}

ligands but remove inhibitory factors to facilitate the implantation process [3]. Many molecules have been proposed as markers for endometrial receptivity, but there is as yet no consensus on which marker is the best. Most of previous studies only focused on a single marker; often the endometrial specimens were not precisely timed; few studies compared the RIF and RM with fertile control at the same time. These may be the potential reasons of the contrasting observation. In addition, the effects of various confounding factors on the result were not examined as well.

Some endometrial receptivity markers expressed in epithelium and others expressed in stroma of the endometrium. Mucin 1(MUC1) is a member-associated protein, highly expressed in luminal and glandular epithelium on LH +7 day $[4,5]$. Fertile women showed a higher level of

(c) The Author(s). 2018 Open Access This article is distributed under the terms of the Creative Commons Attribution 4.0 International License (http://creativecommons.org/licenses/by/4.0/), which permits unrestricted use, distribution, and reproduction in any medium, provided you give appropriate credit to the original author(s) and the source, provide a link to the Creative Commons license, and indicate if changes were made. The Creative Commons Public Domain Dedication waiver (http://creativecommons.org/publicdomain/zero/1.0/) applies to the data made available in this article, unless otherwise stated. 
endometrium MUC1 expression than infertile patients [6]. LIF belongs to interleukin-6 family and has complex regulatory roles in implantation [7]. Animal study showed that blastocysts from LIF knock-out mice failed to implant, however, they were viable when transferred to wild-type recipients with normal endometrium [8]. Integrin is a family of transmembrane glycoprotein that regulates cell-cell and cell-matrix interaction. Integrin isoform $\beta 3$ expression in endometrium coexists with the period of implantation window [9]. Women underwent IVF treatment with normal Integrin $\beta 3$ in endometrium had twice pregnancy rate than women with low Integrin $\beta 3$ level [10]. Abnormal endometrial receptivity may contribute to the reproductive failure. It is postulated that different aspects of endometrial receptivity are disrupted in recurrent implantation failure (RIF) compared with idiopathic recurrent miscarriage (RM). In this study, we studied the expression of three endometrial receptivity markers, MUC1, LIF and Integrin $\beta 3$ in the same endometrium specimens precisely collected at $\mathrm{LH}+$ 7 day and compared among women with RIF, RM and fertile control.

\section{Materials and methods}

\section{Participants and endometrial biopsy}

This study was approved by the ethics committee of The Chinese University of Hong Kong, and informed consent has been obtained from all the participants. Inclusion criteria included women less than 40 years old, with regular menstrual cycle and normal body mass index (BMI), and had no use of hormonal contraception or intrauterine devices for at least 3 months preceding the study. Exclusion criteria included endometrial or uterine pathology such as adenomyosis, fibroids, endometrial polyps and hyperplasia, endometriosis, endometritis, as well as anovulation and polycystic ovary syndrome (PCOS).

RIF was defined as failure to achieve a clinical pregnancy after at least 4 good-quality embryos have been transferred in 3 or more transfer cycles [11]. RM was defined as 3 or more consecutive pregnancy losses before 20-week gestation. All patients were idiopathic with normal uterine cavity examined by ultrasonography and hysterosalpingogram, normal thyroid function, tested negative for lupus anticoagulant and anticardiolipin antibodies, with normal parental karyotype results. Women who had at least one previous live birth within 1-2 years and no history of infertility, implantation failure and miscarriage were included as control.

All participants underwent daily urine test from day 9 of the cycle onwards to identify the LH surge. Endometrial biopsy was obtained using a Pipelle sampler (Prodimed) or Pipet Curet (Cooper Surgical) precisely at $\mathrm{LH}+7$ day. The endometrial specimens were washed immediately in phosphate-buffered saline (PBS, $\mathrm{pH}=7.4$ ) and divided into two parts. One part was fixed in 10\% neutral buffered formalin for immunohistochemistry, the other part was sent to pathology examination for endometrial dating by qualified gynecological pathologist blinded to the clinical diagnosis. If the endometrial dating results were not coincident with the endometrium at mid-secretary phase and have been diagnosed as chronic endometritis, the samples were excluded from the study. Chronic endometritis was defined by presence and diagnostic criteria of CD138 plasma cells as described before [12].

\section{Immunohistochemistry}

After overnight formalin fixation and a serial ethanol dehydration, the endometrial specimens were embedded into paraffin wax and sectioned to a thickness of $4 \mu \mathrm{m}$. Spatial expression of MUC1, LIF and Integrin $\beta 3$ in endometrial specimens were determined by standard immunohistochemistry. In brief, sections were dewaxed in xylene, rehydrated through descending ethanol to PBS, and then quenched in 3\% hydrogen peroxide in methanol for $20 \mathrm{~min}$. Antigen retrieval was performed in microwave oven with $10 \mathrm{mmol} / \mathrm{L}$ sodium citrate buffer $(\mathrm{pH}=6.0)$. Sections were then washed in PBS and blocked in 1\% BSA (bovine serum albumin) buffer for $1 \mathrm{~h}$ at room temperature, then incubated at $4{ }^{\circ} \mathrm{C}$ overnight with primary antibody (goat polyclonal anti-human LIF antibody (1:20, R\&D system, AF-250-NA), mouse monoclonal anti-human MUC1 antibody (1:50, abcam, ab8949), or rabbit polyclonal anti-human $\beta 3$ antibody, (1:50, abcam, ab197662). Then the sections were washed in $0.5 \%$ PBST and incubated in appropriate secondary antibody for $1 \mathrm{~h}$ at room temperature. The specific antibody binding was visualized by peroxidase substrate 3,3'-diaminobenzidene tetrahydrochloride (DAB, Dako) and counterstained with hematoxylin. Sections were then dehydrated and mounted in synthetic resin DPX. The expression of MUC1, LIF and Integrin $\beta 3$ in luminal and glandular epithelium were examined under light microscopy (Leica, Germany). Five visual fields were selected under magnification of 400 for analysis. A qualified field was defined as endometrial tissue occupied $\geq 90 \%$ area with both luminal and glandular epithelium.

\section{H-score analysis}

The intensity of LIF, MUC1 and Integrin $\beta 3$ expression in the endometrial sections were quantified according to the equation: $\mathrm{H}$-score $=\Sigma \mathrm{P}_{\mathrm{i}}$, where $\mathrm{i}$ was referred as staining intensity $(0=$ negative; $1=$ weak; $2=$ moderate; $3=$ strong) and $P_{i}$ was referred as percentage of cells stained at each intensity (0-100\%). H-score of MUC1, LIF and Integrin $\beta 3$ in luminal epithelium and glandular epithelium were obtained in 5 qualified $400 \times$ visual fields per sample, respectively. Each section was scored 
independently by two observers both were blinded to the clinical diagnosis. In the event of differences in the score obtained, slides were reexamined until the $\mathrm{H}$-score for the section agreed by both observers. The final scores were averaged from 5 fields for each sample.

\section{Statistical analysis}

Data were analyzed with SPSS 19.0 (IBM, USA). Quantitative data were compared by Mann-Whitney test, and qualitative data were compared by Chi's square test. $\mathrm{H}$-sores of LIF, MUC1 and Integrin $\beta 3$ were compared by one-way ANOVA, and then post-hoc LSD test for the multiple-pairwise comparisons. Multivariate linear regression was used to test the association between the receptive markers. A value of $P<0.05$ was considered to be significant.

\section{Results}

A total of 78 participants were recruited in this study. Of the 78 endometrial specimens, 8 were excluded due to the histological dating not consistent with mid-secretary phase, and another 11 were excluded due to diagnosed of chronic endometritis and history of endometriosis. Immunohistochemistry study was performed on the remained 59 endometrial specimens, including 20 from fertile controls, 14 from RIF women and 25 from RM. Demographic details are summarized in Table 1. Age, number of previous pregnancy, number of live birth and previous miscarriage were significantly different among three study groups, but not BMI and menstrual cycle length. Women in RIF and RM group were older than control fertile women (both $P<0.001$ ). However, there was no significant correlation between age and expression of LIF, MUC1 and integrin $\beta 3$ in both luminal and glandular epithelium (Additional file 1: Table S1).

MUC1, LIF and Integrin $\beta 3$ expression were identified in both luminal and glandular epithelium, but LIF and Integrin $\beta 3$ can also be found in stromal cells (Fig. 1). MUC1 showed strong immunoreactivity in both luminal and glandular epithelial cells in control group, but less intense in RM group and very low in RIF group. LIF showed positive immunoreactivity in the glandular epithelium than that in the luminal epithelium and stromal cells, but overall the immunoreactivity was not as strong as MUC1. Integrin $\beta 3$ showed positive immunoreactivity in both luminal and glandular epithelium in both RIF and RM groups but less in control group.

The $\mathrm{H}$-score analysis showed that expression of MUC1 in both luminal and glandular epithelium in RIF group was significantly lower than those in control and RM group (Fig. 2). No significant differences in LIF and Integrin $\beta 3$ expression in either luminal or glandular epithelium among and between the three groups were

Table 1 Demographic characteristics of participants

\begin{tabular}{|c|c|c|c|c|}
\hline Variables & Control $(N=20)$ & $\operatorname{RIF}(N=14)$ & $\mathrm{RM}(N=25)$ & $P$-value \\
\hline Age (y) & $28.9 \pm 3.0$ & $35.2 \pm 3.3$ & $36.1 \pm 3.2$ & $<0.001$ \\
\hline $\mathrm{BMI}\left(\mathrm{kg} / \mathrm{m}^{2}\right)$ & $21.7 \pm 1.9$ & $21.9 \pm 2.4$ & $22.9 \pm 3.9$ & 0.43 \\
\hline Smoking (n) & 0/20 (0\%) & 0/14 (0\%) & $3 / 25(12.0 \%)$ & $0.12^{\mathrm{a}}$ \\
\hline Cycle length (d) & $29.4 \pm 1.7$ & $29.1 \pm 2.0$ & $29.8 \pm 4.8$ & 0.89 \\
\hline Abnormal karyotype (n) & $0 / 20(0 \%)$ & 0/14 (0\%) & $0 / 25(0 \%)$ & $N A^{a}$ \\
\hline Progesterone level (nmol/L) & - & $62.4 \pm 33.5$ & $47.3 \pm 20.9$ & $0.31^{\mathrm{b}}$ \\
\hline \multicolumn{5}{|l|}{ No. of previous pregnancy } \\
\hline 0 & $0 / 20(0 \%)$ & 10/14 (71.4\%) & $0 / 25(0 \%)$ & $<0.001$ \\
\hline 1 & $12 / 20(60.0 \%)$ & $3 / 14(21.4 \%)$ & $0 / 25(0 \%)$ & $<0.001$ \\
\hline$\geq 2$ & $8 / 20(40.0 \%)$ & $1 / 14(7.1 \%)$ & 25/25 (100\%) & $<0.001$ \\
\hline \multicolumn{5}{|l|}{ No. of live birth } \\
\hline 0 & $0 / 20(0 \%)$ & 13/14 (92.9\%) & $23 / 25(92.0 \%)$ & $<0.001$ \\
\hline 1 & 14/20 (70.0\%) & $1 / 14(7.1 \%)$ & $2 / 25(8.0 \%)$ & $<0.001$ \\
\hline$\geq 2$ & $6 / 20(30.0 \%)$ & 0/14 (0\%) & 0/25 (0\%) & $<0.001$ \\
\hline \multicolumn{5}{|l|}{ No. of previous miscarriage } \\
\hline 0 & $20 / 20(100 \%)$ & 10/14 (71.4\%) & 0/25 (0\%) & $<0.001$ \\
\hline 1 & 0/20 (0\%) & $3 / 14(21.4 \%)$ & $0 / 25(0 \%)$ & $<0.001$ \\
\hline 2 & 0/20 (0\%) & $1 / 14(7.1 \%)$ & 0/25(0\%) & $<0.001$ \\
\hline$\geq 3$ & $0 / 20(0 \%)$ & 0/14 (0\%) & $25 / 25$ (100\%) & $<0.001$ \\
\hline
\end{tabular}

Data are presented as mean $\pm \mathrm{SD}$ or $\mathrm{n} / \mathrm{N}(\%) . R I F$, recurrent implantation failure; $R M$, recurrent miscarriage. ${ }^{\mathrm{a} C h i}$ square test compared among 3 groups when indicated; ${ }^{\mathrm{b}}$ Mann-Whitney test compared between RIF and RM groups only; NA: not available 


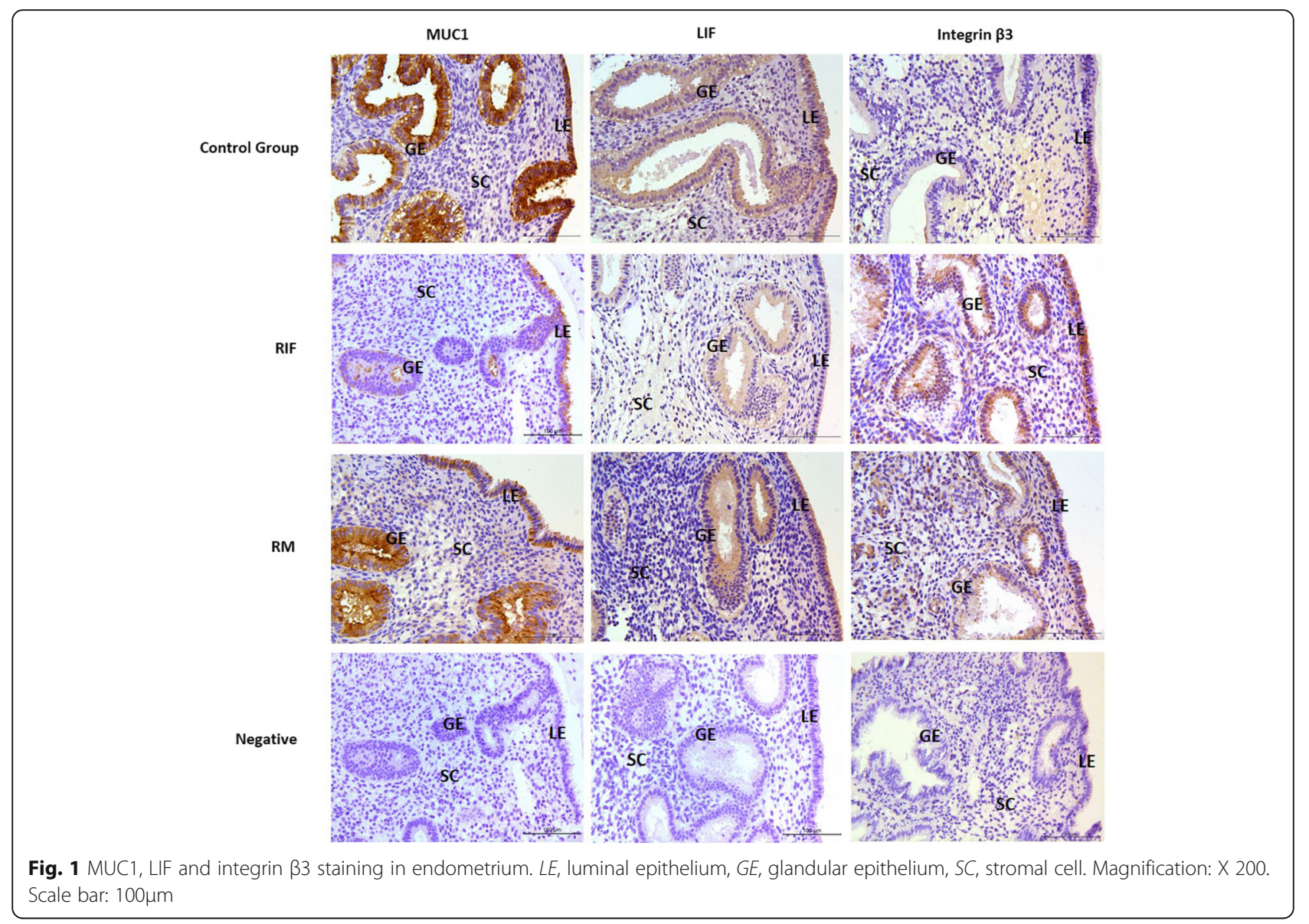

found, although the expression of LIF in luminal and glandular epithelium in RIF group was slightly lower and expression of Integrin $\beta 3$ were slightly higher than other groups. Although chronic endometritis and endometriosis were excluded, there were no significant differences in MUC1, LIF and Integrin $\beta 3$ expressions in the endometrium between women with and women without chronic endometritis and endometriosis (Additional file 1: Table S2).

In multivariate linear regression analysis (Table 2), age, $\mathrm{BMI}$, cycle length, progesterone level, gravidity, parity and previous miscarriage were not significantly associated with endometrial MUC1, LIF and Integrin $\beta 3$ expression levels. The association remained not significant when the multivariate regression analysis was adjusted by the clinical diagnosis.

\section{Discussion}

Recurrent implantation failure and idiopathic recurrent miscarriage present two major challenges of reproductive failure to clinicians providing care for patients who wish to start or extend their family $[13,14]$. The luminal epithelium is the first point of contact between the endometrium and blastocyst, which acts as both barrier and receptor at the same time. In the present study, expression of endometrial receptivity markers LIF, MUC1 and Integrin $\beta 3$ in luminal and glandular epithelium during the implantation window in women with RIF and RM were examined and compared.

MUC1, LIF and Integrin $\beta 3$ have long been proposed as biomarkers for endometrial receptivity. Many studies have been carried out; however, the results were inconsistent (Table 3). A special strength of our study is the precise timing of the specimens; all specimens were obtained precisely 7 days after the LH surge. It is particularly important as endometrial morphology and function change rapidly in the peri-implantation period, so that a difference of only one or two days could have introduced significant variance to the results. It also explains why there was significant controversy regarding the observations reported in the literature. One reason for these discrepancies is the different time point of collecting endometrium biopsy for examination, especially if the biopsy specimens were obtained over a period of several days.

MUC1 has been proposed as an anti-adhesive protein because of its physiochemical hindrance mediated by its long ectodomain, which may inhibit the attachment between blastocyst and endometrium. Animal studies 


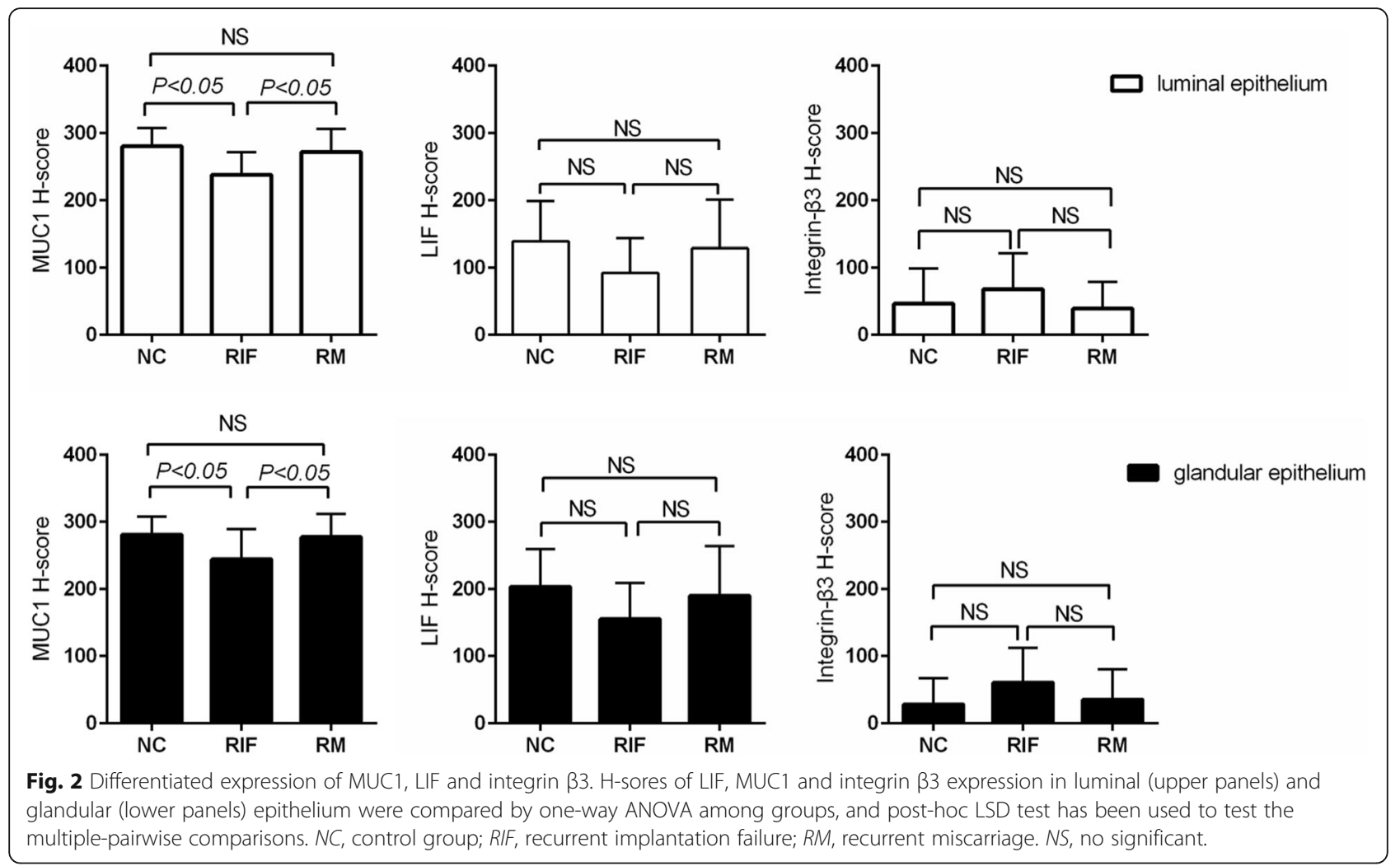

have showed that MUC1 is down-regulated before implantation $[15,16]$, but human studies found that MUC1 is up-regulated during implantation window [4]. Although the precise role of MUC1 in implantation is still unclear, many studies showed low level of MUC1 was associated with impaired receptivity of endometrium [6, 17-19]. Women with RM had reduced endometrial MUC1 expression when compared to fertile women on days $\mathrm{LH}+7$ and 8 [17]. They proposed that decreased expression of MUC1 may induce endometrial super-fertility and interrupt embryo selection, which allows defective blastocysts to implant but leads to increase miscarriage rate. However, our data did not show significantly decrease of MUC1 in RM group, suggesting MUC1 may not be a reliable receptivity marker for RM. In contrast, MUC1 was significantly decreased in RIF group and multivariate linear regression analysis showed MUC1 was independent of demographic and clinical characteristics of the subjects, regardless of RM, RIF or control. It suggests that decreased endometrium MUC1 expression is an independent receptivity marker in RIF during implantation window.

As for Integrin $\beta 3$ in endometrium, we found no significant difference among three study groups. Many investigators like us also failed to find significant change in Integrin $\beta 3$ expression between fertile and RM

Table 2 Multivariate linear regression model of demographic and clinical characteristics

\begin{tabular}{|c|c|c|c|c|c|c|c|c|}
\hline \multirow[t]{2}{*}{ Dependent variables } & \multirow{2}{*}{$\begin{array}{l}\text { Post-hoc } \\
\text { statistical } \\
\text { power } \\
(P<0.05)\end{array}$} & \multicolumn{4}{|c|}{ Model summary } & \multicolumn{3}{|c|}{ Coefficients (constant) } \\
\hline & & $\mathrm{R}$ & $\mathrm{R}^{2}$ & Adjusted $R^{2}$ & $P$ & B & $95 \% \mathrm{Cl}$ & $P$ \\
\hline MUC1 H-score in luminal epithelium & 0.99 & 0.61 & 0.37 & -0.64 & 0.90 & 235.52 & $-370.43-841.48$ & 0.36 \\
\hline MUC1 H-score in glandular epithelium & 0.97 & 0.57 & 0.32 & -0.77 & 0.94 & 226.85 & $-402-48-856.19$ & 0.40 \\
\hline LIF H-score in luminal epithelium & 0.45 & 0.34 & 0.12 & -1.29 & 0.99 & 257.86 & $-1026.67-1542.39$ & 0.63 \\
\hline LIF H-score in glandular epithelium & 0.25 & 0.28 & 0.07 & -1.40 & 1.00 & 384.53 & $-973.02-1742.07$ & 0.50 \\
\hline Integrin $\beta 3 \mathrm{H}$-score in luminal epithelium & 0.99 & 0.68 & 0.50 & -0.39 & 0.79 & -45.99 & $-721.89-629.92$ & 0.87 \\
\hline Integrin $\beta 3 \mathrm{H}$-score in luminal epithelium & 0.96 & 0.55 & 0.31 & -0.81 & 0.95 & 54.47 & - 745.01-853.95 & 0.87 \\
\hline
\end{tabular}

Independent variables include age, $B M I$, cycle length, gravidity, parity, number of previous miscarriage and progesterone level on biopsy day. With or without adjustment of clinical conditions: control, RIF and $\mathrm{RM} ; R$, residual; $R^{2}, \mathrm{R}$ square $B$, beta coefficient $S E$, standard error. $95 \% C l, 95 \%$ confidence interval for $\mathrm{B}$ 
Table 3 Summary of previous inconsistent studies of MUC1, LIF and integrin $\beta 3$ expression in endometrium

\begin{tabular}{|c|c|c|c|c|c|c|c|c|}
\hline Source & & Study (n) & $\begin{array}{l}\text { Fertile } \\
\text { control (n) }\end{array}$ & Timing of biopsy & Methods & MUC1 & LIF & Integrin av $\beta 3 / \beta 3$ \\
\hline \multirow[t]{5}{*}{$\mathrm{RPL} / \mathrm{RM}$} & Xu et al. 2011 & 30 & 26 & $\mathrm{LH}+7-8$ day & Immunohistochemistry & $\downarrow$ & $\leftrightarrow$ & $\leftrightarrow$ \\
\hline & Banerjee et al. 2012 & 36 & 30 & $\mathrm{LH}+5-10$ day & $\begin{array}{l}\text { Immunohistochemistry } \\
\text { Flow cytometric analysis }\end{array}$ & $\downarrow$ & $\downarrow$ & $\downarrow$ \\
\hline & Germeyer et al. 2014 & 21 & 29 & $\mathrm{LH}+5-7$ day & Immunohistochemistry & NA & NA & $\downarrow$ \\
\hline & Karaer et al. 2014 & 30 & 30 & $\mathrm{LH}+6-11$ day & RT-PCR & NA & $\uparrow$ & NA \\
\hline & WU et al.2018 ${ }^{a}$ & 25 & 20 & $\mathrm{LH}+7$ day & Immunohistochemistry & $\leftrightarrow$ & $\leftrightarrow$ & $\leftrightarrow$ \\
\hline \multirow[t]{5}{*}{ RIF } & Mariee et al. 2012 & 45 & 15 & $\mathrm{LH}+7-9$ day & Immunohistochemistry & NA & $\downarrow$ & NA \\
\hline & Coughlan et al. 2013 & 45 & 6 & $\mathrm{LH}+7-9$ day & Immunohistochemistry & NA & NA & $\leftrightarrow$ \\
\hline & Bastu et al. 2015 & 26 & 23 & $\mathrm{LH}+7-9$ day & ELISA \& Western-blot & $\downarrow$ & NA & NA \\
\hline & Comba et al. 2015 & 21 & 20 & $\mathrm{LH}+6-10$ day & ELISA & NA & $\downarrow$ & NA \\
\hline & WU et al. $2018^{a}$ & 14 & 20 & $\mathrm{LH}+7$ day & Immunohistochemistry & $\downarrow$ & $\leftrightarrow$ & $\leftrightarrow$ \\
\hline
\end{tabular}

$R P L$, recurrent pregnancy loss $R M$, recurrent miscarriage $R I F$, recurrent implantation failure $R T$-PCR, quantitative real-time $P C R, E L I S A$, enzyme-linked immunosorbent assay. $\downarrow$ expression significantly reduced; $\leftrightarrow$ expression no significant difference; $\uparrow$ expression significantly increased when compared with control. NA, not available; ${ }^{a}$ present study

women [17, 20, 21], although Germeyer et al. observe that women with unexplained pregnancy loss had significantly reduced Integrin $\beta 3$ expression compared with health control [22]. Coughlan et al. demonstrated that RIF was not associated with abnormal endometrial Integrin expression, and the expression of Integrins $\alpha 1, \alpha 4$, and $\alpha v \beta 3$ have no prognostic value in subsequent IVF treatment [20]. In this study, we also did not find any significant difference in Integrin $\beta 3$ among RM, RIF and fertile control and nor any significant correlation between MUC1, LIF and Integrin $\beta 3$.

In agreement with others, we observed a stronger endometrium staining of LIF in epithelial cells compared with stromal cells. Comba et al. found that both blood and tissue levels of LIF were statistically lower in patients with RPL [23]. Decreased LIF expression level has been demonstrated in RIF patients by other study, when endometrium biopsy was obtained on days $\mathrm{LH}+7$ to $\mathrm{LH}+9$ [24]. However, the results of our study showed no significant difference in expression of LIF among three study groups in both luminal and glandular epithelium, even though $\mathrm{H}$-scores showed a tendency of reduced expression in RIF patients.

There are some limitations of our study. First, the total number of participants included in the study is relatively small. The relative small sample size in each of the three groups studies may result small or subtle differences. Nevertheless, the demonstration of significant reduction of MUC1 expression in this suggests that the difference is likely to be of significant biological relevance. Our current sample size allowed us to show a difference of mean $\mathrm{H}$ score at least 30 with SD 15 with Power 99\% and Type I error of 0.01 . Second, the use of immunohistochemistry to examine the expression of various markers is rather semi-quantitative but it has the advantage of obtaining information of spatial expression of the protein markers in different tissue compartments. In our study, we were able to show that the expression of MUC1 in women with RIF was significantly reduced in the both luminal and glandular epithelium. The use of alternative methods such as quantitative real-time polymerase chain reaction or Western blot will not be able to demonstrate the expression of the protein markers in specific cellular components. Thirdly, although MUC1, LIF and Integrin $\beta 3$ had been separately investigated in different studies, we studied 3 markers simultaneously in the serial sections of same sample; the endometrial specimens were collected precisely during implantation window; and RIF and RM were compared with fertile control in the same study.

\section{Conclusions}

In summary, our study showed MUC1, but not LIF and Integrin $\beta 3$, was significantly decreased in both luminal and glandular epithelium in women with RIF, but not in women with RM. Both LIF and Integrin $\beta 3$ do not appear to be sensitive receptivity markers for RIF or RM. In addition, the reduction in MUC1 expression was an independent marker of endometrial receptivity in women with RIF. It suggests MUC1 contributes to the unexplained reproductive failure in RIF. Further in-depth functional and interventional studies of MUC1 in RIF are needed.

\section{Additional file}

Additional file 1: Table S1. Relationship between female age and receptivity markers. Table $\mathbf{S 2}$. H-score comparison between endometritis/ endometriosis and non-endometritis/non-endometriosis women. (DOCX 16 kb) 


\section{Acknowledgments}

We sincerely thank the women who participated in the study. We also thank the medical and nursing staff of the Reproductive Medical Center of The Price of Wales Hospital for their assistance in patient recruitment and management.

\section{Availability of data and materials}

The data sets used and/or analyzed during the current study are available from the corresponding author on reasonable request.

\section{Authors' contributions}

CCW and TCL designed the study. FW performed the experiments and the statistical analysis with help from HX and BL. XC and YL provided clinical advice and managed the biopsy. FW and CCW wrote the manuscript. All authors reviewed the manuscript. All authors read and approved the final manuscript.

\section{Ethics approval and consent to participate}

This study was approved by the ethics committee of the Prince of Wales Hospital, The Chinese University of Hong Kong. All the participants provided written consent to participate in the study.

\section{Consent for publication}

Not applicable.

\section{Competing interests}

The authors declare that they have no competing interests.

\section{Publisher's Note}

Springer Nature remains neutral with regard to jurisdictional claims in published maps and institutional affiliations.

\section{Author details}

'Department of Obstetrics and Gynaecology, The Chinese University of Hong Kong, Shatin, Hong Kong. ' Li Ka Shing Institute of Health Sciences, Faculty of Medicine, The Chinese University of Hong Kong, Shatin, Hong Kong. ${ }^{3}$ School of Biomedical Sciences, Faculty of Medicine, The Chinese University of Hong Kong, Shatin, Hong Kong.

Received: 23 April 2018 Accepted: 15 June 2018

Published online: 21 June 2018

\section{References}

1. Simón C, Martín JC, Pellicer A. Paracrine regulators of implantation. Bailliere's Best Pract Res Clin Obstet Gynaecol. 2000;14:815-26.

2. Psychoyos A. Hormonal control of Ovoimplantation. Vitam Horm. 1974:31: 201-56.

3. Aplin JD. The cell biological basis of human implantation. Baillieres Best $\mathrm{Pr}$ Res Clin Obs Gynaecol [Internet]. 2000;14:757-64

4. Hey NA, Li TC, Devine PL, Graham RA, Saravelos H, Aplin JD. MUC1 in secretory phase endometrium: expression in precisely dated biopsies and flushings from normal and recurrent miscarriage patients. Hum Reprod. 1995:10:2655-62.

5. Aplin JD, Hey NA, Graham RA. Human endometrial MUC! Carries keratin sulphate: characteristic glycoforms in the luminal epithelium at receptivity. Glycobiol. 1998;8:269-76.

6. Margarit L, Taylor A, Roberts MH, Hopkins L, Davies C, Brenton AG, et al. MUC1 as a discriminator between endometrium from fertile and infertile patients with PCOS and endometriosis. J Clin Endocrinol Metab. 2010;95: 5320-9.

7. Kimber SJ. Leukaemia inhibitory factor in implantation and uterine biology. Reproduction. 2005;130:131-45.

8. Stewart CL, Kaspar P, Brunet LJ, Bhatt H, Gadi I, Köntgen F, et al. Blastocyst implantation depends on maternal expression of leukaemia inhibitory factor. Nature [Internet]. 1992;359:76-9.

9. Lessey BA, Castelbaum AJ, Wolf L, Greene W, Paulson M, Meyer WR, et al. Use of integrins to date the endometrium. Fertil Steril. 2000;73:779-87.

10. Thomas K, Thomson A, Wood S, Kingsland C, Vince G, Lewis-Jones I. Endometrial integrin expression in women undergoing in vitro fertilization and the association with subsequent treatment outcome. Fertil Steril. 2003;80:502-7.
11. Coughlan C, Ledger W, Wang Q, Liu F, Demirol A, Gurgan T, et al. Recurrent implantation failure: definition and management. Reprod BioMed Online. 2014;28:14-38

12. Liu Y, Chen $X$, Huang J, Wang CC, Yu MY, Laird S, et al. A comparison of the prevalence of chronic endometritis determined by the use of different diagnostic methods in women with and without reproductive failure. Fertil Steril. 2018; in press

13. Teklenburg G, Salker M, Heijnen C, Macklon NS, Brosens JJ. The molecular basis of recurrent pregnancy loss: impaired natural embryo selection. Mol Hum Reprod. 2010;16:886-95.

14. Orlando J, Coulam C. Is Superfertility associated with recurrent pregnancy loss? Am J Reprod Immunol. 2014;72:549-54.

15. Surveyor GA, Gendler SJ, Pemberton L, Das SK, Chakraborty I, Julian J, et al. Expression and steroid hormonal control of muc-1 in the mouse uterus. Endocrinology. 1995:136:3639-47.

16. DeSouza MM. Reduction of mucin-1 expression during the receptive phase in the rat uterus [in process citation]. Biol Reprod [Internet]. 1998;58:1503-7.

17. Xu B, Sun X, Li L, Wu L, Zhang A, Feng Y. Pinopodes, leukemia inhibitory factor, integrin- $\beta 3$, and mucin-1 expression in the peri-implantation endometrium of women with unexplained recurrent pregnancy loss. Fertil Steril. 2012;98:389-95.

18. Horne AW, Lalani EN, Margara RA, Ryder TA, Mobberley MA, White JO. The expression pattern of MUC1 glycoforms and other biomarkers of endometrial receptivity in fertile and infertile women. Mol Reprod Dev. 2005;72:216-29

19. Bastu E, Mutlu MF, Yasa C, Dural O, Aytan AN, Celik C, et al. Role of Mucin 1 and Glycodelin $A$ in recurrent implantation failure. Fertil Steril [Internet]. 2015;103:1059-1064.e2.

20. Coughlan C, Sinagra M, Ledger W, Li TC, Laird S. Endometrial integrin expression in women with recurrent implantation failure after in vitro fertilization and its relationship to pregnancy outcome. Fertil Steril. 2013;100:825-30.

21. Tuckerman EM, Laird SM, Prakash A, Li TC. Expression of integrins in the endometrium of women with recurrent miscarriage. Fertil Steril. 2006;86:755-7.

22. Germeyer A, Savaris RF, Jauckus J, Lessey B. Endometrial beta3 integrin profile reflects endometrial receptivity defects in women with unexplained recurrent pregnancy loss. Reprod Biol Endocrinol. 2014;12:1-5.

23. Comba C, Bastu E, Dural O, Yasa C, Keskin G, Ozsurmeli M, et al. Role of inflammatory mediators in patients with recurrent pregnancy loss. Fertil Steril. 2015;104:1467-1474.e1.

24. Mariee N, Li TC, Laird SM. Expression of leukaemia inhibitory factor and interleukin 15 in endometrium of women with recurrent implantation failure after IVF; correlation with the number of endometrial natural killer cells. Hum Reprod. 2012;27:1946-54.

\section{Ready to submit your research? Choose BMC and benefit from}

- fast, convenient online submission

- thorough peer review by experienced researchers in your field

- rapid publication on acceptance

- support for research data, including large and complex data types

- gold Open Access which fosters wider collaboration and increased citations

- maximum visibility for your research: over $100 \mathrm{M}$ website views per year

At BMC, research is always in progress.

Learn more biomedcentral.com/submissions 